\title{
O estágio de observação e suas contribuições no campo da educação: uma análise na
}

\section{formação de professores}

\author{
The observation stage and its contributions in the field of education: an analysis in teacher
} education

La etapa de observación y sus aportes en el campo de la educación: un análisis en la formación del profesorado

\section{Resumo}

Os estágios na formação de professores possibilitam vivências e experiências no campo da educação que precisam ser socializadas. Pensando nisso, o presente artigo buscou analisar as contribuições presentes no estágio de observação de uma estudante de Licenciatura em Ciências Biológicas, de uma instituição pública brasileira, localizada na região noroeste do estado do Rio Grande do Sul, atentando para um debate epistêmico e analítico no campo da educação, com vistas a promover um repensar na formação de professores em um contexto remoto de ensino. A metodologia adotada consistiu de uma pesquisa qualitativa, do tipo descritiva, cuja coleta de dados se deu por meio de um diário de bordo e, para a análise dos dados, optou-se pela Análise Textual Discursiva. As atividades remotas, devido a pandemia provocada pelo Novo Coronavírus, trazem consigo situações desafiadoras, tanto para os professores, quanto para os estagiários e alunos. Nesse sentido, é plausível dizer que os estágios oportunizam novas vivências, permitindo um (re)pensar na atuação do professor para a mediação do conhecimento na contemporaneidade.

Palavras-chave: Ensino; Saberes; Atividades; Experiências.

\begin{abstract}
The internships in teacher training enable experiences in the field of education that need to be socialized. With this in mind, this article sought to analyze the contributions present in the observation stage, of a graduate student in Biological Sciences from a Brazilian public institution, located in the northwest region of the state of Rio Grande do Sul, paying attention to an epistemic and analytical debate in the field of education, with a view to promoting a rethinking of teacher training in a remote teaching context. The adopted methodology consisted of a qualitative research, of the descriptive type, whose data collection was done through a logbook and, for the analysis of the data, we opted for the Discursive Textual Analysis. Remote activities, due to the pandemic caused by the New Coronavirus, bring with them challenging situations, both for teachers, as well as for interns and students. In this sense, it is
\end{abstract}


plausible to say that internships provide opportunities for new experiences, allowing one to (re) think about the teacher's performance for the mediation of knowledge in contemporary times.

Keywords: Teaching; Knowledge; Activities; Experiences.

\section{Resumen}

Las pasantías en la formación del profesorado posibilitan experiencias en el campo de la educación que necesitan ser socializadas. Con esto en mente, este artículo buscó analizar los aportes presentes en la etapa de observación, de un estudiante de posgrado en Ciencias Biológicas de una institución pública brasileña, ubicada en la región noroeste del estado de Rio Grande do Sul, atendiendo a una situación epistémica y debate analítico en el campo de la educación, con miras a promover un replanteamiento de la formación del profesorado en un contexto de enseñanza a distancia. La metodología adoptada consistió en una investigación cualitativa, de tipo descriptivo, cuya recolección de datos se realizó a través de un cuaderno de bitácora y, para el análisis de los datos, se optó por el Análisis Textual Discursivo. Las actividades remotas, debido a la pandemia provocada por el Nuevo Coronavirus, traen consigo situaciones desafiantes, tanto para profesores, como para pasantes y estudiantes. En este sentido, es plausible decir que las pasantías brindan oportunidades para nuevas experiencias, permitiendo (re) pensar en el desempeño del docente para la mediación del conocimiento en la época contemporánea.

Palabras clave: Enseñanza; Conocimiento; Actividades; Experiencias.

\section{Introdução}

Os estágios se configuram como um importante campo de socialização de vivências e experiências, contribuindo com a formação de professores. Por meio dos estágios, os professores em formação inicial e/ou continuada adquirem novos conhecimentos, bem como refletem sobre o processo de ensino e aprendizagem, o uso de metodologias de ensino e, ainda, as diversas intempéries e especificidades presentes no dia a dia docente.

Os estágios, sendo um momento de compartilhamento de saberes, possibilitam aos estudantes a implementação de novos recursos didáticos, buscando construir um ambiente profícuo para novas aprendizagens. Da mesma forma, os estágios visam um aperfeiçoamento no processo formativo de professores, atentando para as questões sociais, educacionais, políticas, históricas, econômicas e ambientais. Os estágios devem instigar um repensar na escola, nos alunos, na comunidade, no professor e permear práticas e ações que vão além do processo de memorização de conteúdos.

Quando se discute a importância dos estágios na formação de professores, deve-se atentar para as questões emergentes, como por exemplo, a saúde, as desigualdades sociais, a polissemia de saberes, buscando um diálogo constante entre professores e alunos. Por meio do diálogo os alunos compartilham suas experiências e, o professor em formação inicial cria a sua identidade, direcionando o currículo a sua turma.

Pensando na relevância dos estágios, é cabível considerar o seu processo formativo, sendo uma construção e intervenção social, haja vista que o acadêmico observa, analisa, pensa e reflete sobre as especificidades presentes no campo da educação. Por este viés, pode-se dizer que os acadêmicos em formação inicial, enquanto estão em estágio, eles conseguem ter novas aprendizagens com os professores que já possuem experiências. No mesmo sentido, os estagiários aprendem a ministrar aulas, conhecem a escola, o conteúdo da disciplina e refletem constantemente acerca das aulas observadas/ministradas, ou seja, o estágio proporciona vivências e experiências singulares, sendo que o estagiário desenvolve habilidades e competências que são fundamentais para futura profissão.

Por meio dos estágios, os professores em formação constroem uma bagagem de novos conhecimentos, debatendo e repensando as questões políticas, sociais, culturais, educacionais, com vistas a construir uma aprendizagem significativa e que apresente representatividade na sociedade. Quando se discute a relevância dos estágios, se pensa no desenvolvimento da criatividade e na implementação de novas práticas educativas.

As instituições de ensino superior devem estimular o desenvolvimento dos estágios nos cursos de licenciatura e as trocas de experiências entre as escolas, promovendo novos diálogos e um trabalho colaborativo entre os diferentes níveis de ensino. Nesse contexto, os professores que já apresentam vivências devem estimular os estagiários a se inserirem em atividades 
pedagógicas e de ensino, permitindo um constante questionamento sobre os conteúdos mediados em sala de aula e as especificidades presentes no dia a dia do professor. Frente a isso, o estágio atua diretamente no processo formativo do acadêmico de licenciatura, desenvolvendo o processo de ensino e aprendizagem e possibilitando novas estratégias, vivências, saberes e trocas de conhecimentos em sala de aula, que auxiliam na construção identitária e na atuação na sociedade.

Sabe-se que os estágios são momentos desafiadores na vida do estudante, entretanto, ele deve ser tema de debates e discussões, com vistas a contribuir com o campo educacional e formativo. Pensando nisso, o presente artigo buscou analisar as contribuições presentes no estágio de observação de uma estudante de Licenciatura em Ciências Biológicas, de uma instituição pública brasileira, localizada na região noroeste do estado do Rio Grande do Sul, atentando para um debate epistêmico e analítico no campo da educação, com vistas a promover um repensar na formação de professores em um contexto remoto de ensino.

\section{Referencial Teórico}

Nos cursos de formação de professores os estágios devem contribuir com a construção de novos conhecimentos, saberes, vivências e experiências, possibilitando que o docente desenvolva competências e habilidades para desempenhar um papel ativo e reflexivo, tanto em sala de aula, quanto no meio social. Para Perrenoud et al. (2001, p. 139), "os estágios constituem o lugar privilegiado da formação prática. Eles permitem ao iniciante adquirir as 'habilidades' do ofício na companhia de práticos experiente". Noutras palavras, o aluno estagiário ao observar o professor atuante, ele consegue compreender e inserir estes conhecimentos a sua vivência. Adicionalmente, ao desenvolver o estágio de regência, consegue atuar de forma responsável e crítica no campo educacional.

Segundo Tardif (2002), cada professor apresenta os seus saberes. Pensando nisso, pode-se dizer que os saberes docentes são adquiridos nas práticas diárias em sala de aula e nas trocas de conhecimentos entre alunos e professores. É plausível comentar que os saberes docentes estão em constantes transformações, visto que cada sujeito apresenta a sua bagagem de saberes e, quando ocorre a socialização, ocorre também o surgimento de novos conhecimentos. Pode-se dizer que “Aprender a ser professor caracteriza-se, portanto, por um permanente envolvimento pessoal, relacional e situacional, em que as experiências emocionais emergem inevitavelmente relacionadas com os papéis e funções inerentes à profissão, experienciados pela primeira vez em contexto de estágio" (Gomes, Queirós, Batista, 2019, p. 7).

No campo da educação os estágios são fundamentais para a construção identitária dos professores, visando uma atuação responsável, reflexiva e construtiva dentro da sala de aula com prováveis reflexos na sociedade. Por meio dos estágios, os docentes em formação inicial, começam a adquirir o gosto pela profissão docente, experienciando novas descobertas, conhecimentos e aperfeiçoando a sua didática. Cada professor apresenta a sua forma de ministrar as aulas e despertar o interesse dos alunos, entretanto, deve-se haver constantes diálogos e reflexões sobre as condições e as especificidades de cada aluno buscando, sempre que possível, inserir todos os alunos no processo de ensino e aprendizagem (Silveira \& Golle, 2019).

O professor deve ser visto como um mediador dentro da sala de aula, estimulando um pensar crítico, reflexivo e emancipatório dos seus alunos. Pensando nisso, pode-se dizer que a educação deve ser libertadora, com vistas a (des)construir conceitos e promover novos questionamentos sobre as questões emergentes e hegemônicas que contemplam o dia a dia dos sujeitos (Freire, 2004). Os estágios na formação de professores devem inserir as vivências dos alunos na dinâmica aula e, ainda, pautar-se no diálogo e na socialização de novos conhecimentos, buscando respostas aos problemas sociais, educacionais, políticos, econômicos e ambientais.

Pimenta e Lima (2009) abordam que os estágios se configuram como uma importante forma de intervenção social, inserindo sujeitos com diferentes vivências e experiências em sala de aula. Da mesma forma, os estágios oportunizam um crescimento pessoal e profissional do professor em formação, visto que ele observa, analisa e reflete sobre o contexto 
educacional e as formas para mediar os conhecimentos. Sendo assim, pode-se dizer que o professor precisa repensar sua prática pedagógica, a partir de suas vivências no campo educacional, bem como refletir sobre seus métodos de ensino e buscar, quando necessário, novas metodologias para mediar o conhecimento, haja vista que o professor precisa ser um pesquisador da sua prática de ensino. Para Silveira et al. (2020, p. 38):

A formação de professores é uma temática que necessita de constantes diálogos, debates e provocações, visto que insere uma diversidade de saberes, vivências e experiências. Cada professor apresenta a sua didática, bem como a sua forma de mediar o conhecimento, ou seja, cada docente apresenta a sua identidade dentro do ambiente escolar, oriunda do seu processo de formação.

Quando se discute os estágios na formação de professores, cria-se um contexto de provocações sobre quais saberes são necessários na contemporaneidade e como melhorar o ensino e a aprendizagem, visto que há uma diversidade de saberes, bem como desafios sociopolíticos, culturais, ambientais, econômicos e que (inter)ferem no processo de construção do conhecimento. Demo (2001) salienta que o professor precisa saber de forma inequívoca e analítica a condição de aprendizagem do aluno, pois é ele que está diretamente com os estudantes. Por isso a necessidade de constantes diálogos dentro da sala de aula e, o estágio deve permitir discussões profundas sobre temáticas que circundam o dia a dia de alunos e professores. Na mesma sequência, Dallazem (2020, p. 7) discute que "Torna-se imprescindível que professores planejem suas atividades com base em estudos e pesquisas que lhe oportunizem o conhecimento acerca de seus conteúdos, mas também acerca do processo de aprendizado das crianças, reconhecendo suas especificidades de forma a desenvolver um trabalho de qualidade".

No campo educacional, dentre as diversas incumbências presentes no dia a dia do professor, uma delas é o ato de mediar o conhecimento aos alunos, visando estabelecer relações entre as questões educacionais e as temáticas emergentes na sociedade. Pensando nos estágios, pode-se dizer que eles oportunizam os professores a criarem o hábito de refletirem sobre a sua forma de abordar o conhecimento em sala de aula, bem como testarem e aplicarem metodologias que despertem nos alunos a atenção e o gosto pelo conhecimento. Pode-se dizer que "Os estágios, tanto de observação quanto de regência de classe, são práticas socioculturais que tangenciam o saber teórico com o prático, possibilitando vivências que deleitam em ações sociais" (Silveira \& Golle, 2019, p. 70).

O professor, quanto está em campo de estágio, precisa instigar o pensamento crítico e reflexivo de seus alunos. Para isso ocorrer é imprescindível o processo de ação e reflexão, uma vez que a cada aula ministrada o professor reflete sobre as condições estabelecidas para que os alunos possam expressar seus conhecimentos. Quando o professor reflete ele está sendo um pesquisador da sua prática pedagógica e, ainda, está buscando melhorar seus saberes. Este processo de ação e reflexão contribuem com a qualidade da educação, contribuindo com uma formação humana, crítica e reflexiva de docentes, com vistas a formarem estudantes dotados de valores e condutas sociais (Schön, 2000).

A educação precisa ser libertadora e os estágios devem contemplar o debate e, acima de tudo, novos olhares ao campo da educação, buscando analisar e avaliar as especificidades dos docentes. Os estágios devem contribuir com o desenvolvimento social, político, cultural, econômico e ambiental dos sujeitos envolvidos. Tanto alunos quanto professores em formação inicial e/ou continuada devem adquirir habilidades para atuarem de forma crítica e responsável na sociedade, pautando práticas e ações que favoreçam no processo de emancipação social, mitigando casos de alienação social e ideológica (Freire, 2004).

\section{Metodologia}

A presente pesquisa apresenta uma abordagem metodológica do tipo qualitativa. Na visão de Minayo (2011), as 
pesquisas qualitativas envolvem as percepções e opiniões do pesquisador por meio de uma análise minuciosa de fatos e circunstâncias presentes na sociedade. Em se tratando deste estudo, ocorreram diversas análises e anotações, instigando um repensar no processo formativo de um docente em campo de estágio, buscando novas reflexões acerca das questões metodológicas adotadas em sala de aula, os desafios presentes no dia a dia professor e a interação dos alunos em um contexto remoto de ensino.

Da mesma forma, em se tratando de metodologia, a presente pesquisa é do tipo explicativa. Para Severino (2016), as pesquisas denominadas explicativas buscam analisar e identificar os fenômenos e suas causas por meio da interpretação de dados qualitativos. Para a coleta de dados utilizou-se um diário de bordo da aluna estagiária, cuja análise dos dados pautou-se na Análise Textual Discursiva, visto que implica em uma “[...] ruptura com o paradigma dominante de ciência, fundamentado em suposta verdade, objetividade e neutralidade. Nesse tipo de análise exige-se de o pesquisador mergulhar em seu objeto de pesquisa, assumindo-se sujeito e assumindo suas próprias interpretações" (Moraes \& Galiazii, 2006, p. 122). No mesmo sentido, Medeiros e Amorim (2017, p. 250) comentam que:

No que toca a Análise Textual Discursiva, descrição e interpretação são vistas também como elementos da análise; contudo, diferente da Análise de Conteúdo, tais elementos se desenvolvem em momentos concomitantes. A interpretação segue uma visão hermenêutica de reconstrução de significados com acento na perspectiva dos sujeitos envolvidos na pesquisa. Ela não adota exclusivamente uma teoria específica do início ao fim, pois, vislumbra, na maior parte das vezes, produzir teorias no processo da investigação.

Em se tratando da Análise Textual Discursiva, pode-se dizer que ela visa a unitarização dos dados em subunidades, por meio do olhar empírico do pesquisador. Conforme o pesquisador vai fazendo compreensões, ele pode dividir o texto em muitas outras unidades, buscando uma análise minuciosa dos dados (Moraes \& Galiazzi, 2006).

\section{Resultados e Discussão}

O estágio de observação consiste em uma primeira etapa formativa antes da regência de classe. Por meio do estágio de observação, o professor em formação inicial desenvolve habilidades e competências que são fundamentais para a sua efetiva prática pedagógica. Na visão de Freire (2004, p. 29) "a formação docente consiste em um processo de formação permanente", ou seja, sempre há algo a se aprender, por isso a necessidade de discussões e debates no campo da educação.

Durante os momentos de estágio que foram desenvolvidos em uma instituição pública do noroeste do estado do Rio Grande do Sul, com o segundo ano do ensino médio na disciplina de Biologia, foi possível perceber as adversidades presentes no dia a dia do professor, principalmente em um contexto remoto de ensino devido a pandemia provocada pelo Novo Coronavírus. O presente estágio é tema da disciplina denominada Estágio Curricular Supervisionado III de um curso de Licenciatura em Ciências Biológicas de uma instituição pública de ensino superior localizada na região noroeste do estado do Rio Grande do Sul.

O desenvolvimento do estágio de observação ocorreu num período de quatro semanas, entre os meses de outubro e novembro do ano de 2020, ocorrendo dois encontros semanais, um na terça-feira e outro na quinta-feira, perdurando uma hora e vinte minutos cada encontro. As aulas ministradas pela professora regente tinham o propósito de sanar as dúvidas dos alunos, visto que os conteúdos curriculares estavam dispostos no ambiente virtual. Durante as observações foi possível perceber que a professora buscava interagir com os alunos questionando-os acerca de suas dúvidas, entretanto, era notório que muitos alunos não demostravam interesse. Observou-se também que a maioria dos alunos estavam com suas câmeras e os microfones desligados, portanto, não há como afirmar se todos estavam presentes durante as aulas. Na visão de Perrenoud (2002), por meio dos estágios os estudantes de licenciaturas conseguem diagnosticar as intempéries presentes no dia a dia do professor, pois eles estão observando, analisando e anotando para, posteriormente, quando iniciarem a regência de classe, inserir novas 
metodologias e recursos didáticos no campo do conhecimento.

Este contexto remoto de ensino traz consigo diversas provocações, como por exemplo, a importância do professor para debater informações, principalmente, as que estão presentes nos meios de comunicação e não apresentam cientificidade. Da mesma forma, a necessidade de instigar a autonomia do aluno na busca pelo conhecimento e inseri-los nas discussões dentro do ambiente virtual. Para Nóvoa (1991, p. 5) "Estar em formação implica em investimento pessoal, um trabalho livre e criativo sobre os percursos e os projetos próprios, com vistas à construção de uma identidade que também é uma identidade profissional". Os estágios na formação de professores apresentam esta característica de auxiliar na formação identitária dos professores e alunos para as (con)vivências sociais.

Pode-se dizer que o professor neste contexto de ensino remoto teve que ampliar os seus saberes, principalmente acerca do uso da Tecnologias da Informação e Comunicação, com vistas a contribuir no processo de mediação do conhecimento. Na visão de Kubata et al. (2011, p. 2):

A postura do professor em sala de aula, bem como suas artimanhas em articular o conteúdo teórico a ser ensinado com atividades mais dinâmicas e uma abordagem moderna são, sem dúvida, pontos de partida para a solução de problemas em sala de aula, tanto no sentido disciplinar (comportamento do aluno) quanto no índice de rendimento de conteúdos que serão aproveitados pelo estudante.

Dentre os desafios e dificuldades observados durante o estágio de observação destacam-se: a falta e/ou instabilidade de conexão com a internet, a pouca participação dos alunos e a necessidade de abordagem de uma aula essencialmente expositiva devido à falta de diálogo e interação da turma. Situações como estas se tornam um desafio no dia a dia do professor e os estágios permitem estas reflexões e discussões, visando encontrar alternativas para sanar estes desafios.

\section{Considerações Finais}

O estágio se caracteriza como uma importante forma de intervenção social, instigando um repensar na formação de professores, oportunizando uma troca constante de conhecimentos, vivências e experiências. Os estágios devem inserir conhecimentos sociais, políticos, ambientais, culturais, educacionais e que apresentem relação com o cotidiano dos alunos, visando buscar respostas a problemas que emergem na sociedade. O professor em formação, quando está em campo de estágio, precisa ter um olhar crítico ao processo de ensino e aprendizagem e, sempre que possível deve testar novas metodologias, recursos didáticos e, ainda, refletir sobre a sua forma de atuação em sala de aula.

$\mathrm{O}$ atual período vivenciado pela população, devido a pandemia provocada pelo Novo Coronavírus e os debates sociopolíticos, traz consigo provocações necessárias, como por exemplo, o professor é uma figura que precisa de melhores condições de trabalho, respeito e valorização, visto que ele contribui na formação dos sujeitos para as vivências em sociedade. Ainda, o professor deve atuar de forma a mitigar casos de alienação social e ideológica e, os estágios na formação de professores, ao inserirem os estudantes de licenciaturas nos ambientes educacionais, permitem novos olhares e debates no processo de ensino e aprendizagem, atentando para as práticas sociais e educacionais. O estágio de observação que ocorreu em uma instituição pública do estado do Rio Grande do Sul oportunizou reflexões profundas no campo formativo docente, visto que a formação de professores necessita de constantes pesquisas, cursos formativos e diálogo com os diferentes saberes sociais.

\section{Agradecimentos}

De forma especial agradecemos aos autores pelas colaborações profícuas na escrita deste artigo, bem como a Coordenação de Aperfeiçoamento de Pessoal de Nível Superior - CAPES pela bolsa PIBID durante a graduação de um dos integrantes, bolsa CAPES em nível de mestrado e doutorado de outros membros deste trabalho. Com certeza o fomento a 
Research, Society and Development, v. 10, n 4, e18510414074, 2021

(CC BY 4.0) | ISSN 2525-3409 | DOI: http://dx.doi.org/10.33448/rsd-v10i4.14074

iniciação à docência e a pesquisa favorece no desenvolvimento das pesquisas e no compartilhamento de novos resultados.

\section{Referências}

Dallazem, A. (2020). Práticas educativas, memórias e oralidades. Rev. Pemo-Revista do PEMO, Fortaleza, 2(1), 1-10.

Demo, P. (2001). Educação \& conhecimento: relação necessária, insuficiente e controversa. Vozes.

Freire, P. (2004). Pedagogia da autonomia: saberes necessários à prática educativa: Paz e Terra.

Gomes, P. M. S., Queirós, P. M. L., \& Batista, P. M. F. (2019). Aprender a ser professor em contexto de estágio: um estudo com recurso a timelines em entrevistas de natureza bibliográfica. Revista Brasileira de Educação, 24, e240015.

Kubata, Fróes, R. C., Fontanezi, R. M. M., \& Bernabé, F. H. L. (2011). A postura do professor em sala de aula: atitudes que promovem bons comportamentos e alto rendimento educacional. Revista Eletrônica de Letras. p. 1-26.

Medeiros, E. A. de, \& Amorim, C. C. (2017). Análise textual discursiva: dispositivo analítico de dados qualitativos para a pesquisa em educação. Laplage em revista. Sorocaba. 3(3), 247-260.

Minayo, M. C. de S. (2011). Pesquisa social: teoria, método e criatividade. Editora Vozes Limitada.

Moraes, R., \& GaliazzI, M. do C. (2006). Análise Textual Discursiva: processo reconstrutivo de múltiplas faces. Ciência \& Educação. Bauru. 12(1), 117-128.

Nóvoa, A. (1991). A formação contínua de professores: realidades e perspectivas: Universidade de Aveiro.

Perrenoud, P. (2002). A prática reflexiva no ofício do professor: profissionalização e razão pedagógica: Artmed.

Perrenoud, P., et. al. (2001). Formando professores profissionais. Quais estratégias? Quais competências? Tradução Fátima Murad e Eunice Gruman. (2a. ed.): Artmed.

Pimenta, S. G., \& Lima, M. S. L. (2017). Estágio e docência. (3a ed.): Cortez.

Schön, D. (2000). Educando o profissional reflexivo: um novo design para o ensino e a aprendizagem: Artmed.

Silveira, D. P. da, \& Golle, D. P. (2019). Confeccionando o seu relatório de estágio para cursos de licenciaturas: um enfoque nas Ciências Biológicas: Editora Appris.

Silveira, D. P., Soares, E. G., SIlva, J. C. S. da, \& Veiga, D. J. S. da. (2020). Uma análise multidimensional na formação de professores: tecendo um novo olhar o campo da educação. Revista Di@logus, Cruz Alta, 9(3), 37-45.

Silveira, D. P. da, \& Golle, D. P. (2019). O estágio no ensino superior como prática sociocultural para a construção de saberes significativos na contemporaneidade. Revista missioneira. Santo Ângelo, 21(2), 67-75.

Severino, A. J. (2016). Metodologia do trabalho científico. (24a ed.): Cortez.

Tardif, M. (2002). Saberes docentes e formação profissional. (4a ed.): Vozes. 